\title{
Synthesis and Bioactivity of Novel Acetylenic Compounds
}

\author{
Toshitsugu Fukumaru, Hiroshi Awata, Noritaka Hamma \\ and Toshiaki Komatsu \\ Takarazuka Research Laboratory, Sumitomo Chemical Co., Takarazuka, Hyogo \\ Received September 12, 1974
}

\begin{abstract}
The synthesis of novel acetylenic ketone compounds and anti-inflammatory and antimicrobial activities are herein described.
\end{abstract}

It is well known that acetylenic compounds have remarkable antimicrobial activity. ${ }^{11}$ However, to our surprise, we have also found that acetylenic compounds, particularly conjugated acetylenic ketones, have marked anti-inflammatory activity.

In the course of our intensive research to discover new anti-inflammatory agents in natural products, we isolated a very active substance, which was proved to be Caplillin reported previously by Imai. ${ }^{2)}$ We then discovered that some of the known synthetic acetylenic compounds ${ }^{3)}$ also have anti-inflammatory activity.

Based on this new knowledge, we synthesized a large number of the various classes of novel acetylenic compounds and examined their antiinflammatory activity, gastrointestial disturbance and antimicrobial activity.

\section{MATERIALS AND METHODS}

1) Synthesis of monoacetylenic ketones. The general method $\mathbf{I}$, involving the alkylation of aldehydes with ethynyl magnesium bromides ${ }^{4)}$ and oxidation of propargylic alcohols to conjugated ketones was used as described in the following scheme
In a few cases, a direct ketone synthesis method was used as described below;

A representative example is the following;

4-Phenoxy-tetrolophenone

A solution of ethyl magnesium bromide which was prepared from $6 \mathrm{~g}$ of ethyl bromide and $1.3 \mathrm{~g}$ of magnesium in $50 \mathrm{ml}$ of anhydrous tetrahydrofuran was added to a solution of $6.8 \mathrm{~g}$ of 1-phenoxy-2propyne in $10 \mathrm{ml}$ of anhydrous tetrahydrofuran at room temperature. After stirring for $2 \mathrm{hr}$, the reaction mixture was cooled to below $0^{\circ} \mathrm{C}$ and $5.3 \mathrm{~g}$ of benzaldhyde was then added under cooling and the mixture was left overnight.

Decomposition of the complex with $50 \mathrm{ml}$ of saturated aqueous ammonium hydrochloride, dilution with water, acidification with hydrochloric acid, extraction with ether, washing with water, drying and evaporation of the solvent yielded $12.0 \mathrm{~g}$ of crude 1 phenyl-1-hydroxy-4-phenoxy-2-butyne as a solid, which was dissolved in $300 \mathrm{ml}$ of anhydrous acetone. To this solution was added $120 \mathrm{~g}$ of active manganese dioxide and the mixture was vigorously stirred for $4 \mathrm{hr}$ at room temperature under an atmosphere of nitrogen. Removal of manganese dioxide with a Celite column, evaporation of the solvent, crystallization with a mixture of ether and $\eta$-hexane and recrystallization from a mixture of acetone and methanol yielded $7.8 \mathrm{~g}$ of 4-phenoxy-tetrolophenone. $\operatorname{mp} 59.5 \sim 61.0^{\circ} \mathrm{C}$ IR ${ }_{\max }^{\mathrm{Najol}}: 2230 \mathrm{~cm}^{-1}, 1650 \mathrm{~cm}^{-1}$. NMR $\partial_{\mathrm{TMS}}^{\mathrm{CDCl}_{3}} 4.92$ (s, 2H), aromatic protons. Anal. Found: C, 81.59;

$$
\begin{aligned}
& \mathrm{R}^{\prime} \mathrm{C} \equiv \mathrm{CH} \stackrel{\mathrm{EtMgBr}}{\longrightarrow} \mathrm{R}^{\prime} \mathrm{C} \equiv \mathrm{CMgBr} \stackrel{\mathrm{RCHO}}{\longrightarrow} \mathrm{R} \underset{\mathrm{O}}{\mathrm{d} H \mathrm{H}} \stackrel{\mathrm{CH}}{\mathrm{C}} \\
& \stackrel{\mathrm{MnO}_{2}}{\longrightarrow} \underset{\mathrm{O}}{\mathrm{R}-\mathrm{CC}} \stackrel{\mathrm{H}}{\stackrel{\mathrm{H}}{\mathrm{O}}} \stackrel{\mathrm{CR}}{ }
\end{aligned}
$$

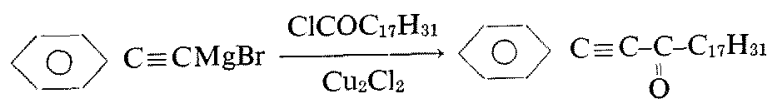




\section{$\mathrm{H}$, 4.94. Calcd. for $\mathrm{C}_{16} \mathrm{H}_{12} \mathrm{O}_{2}: \mathrm{C}, 81.34 ; \mathrm{H}, 5.12$.}

2) Synthesis of diacetylenic ketones. For the preparation of diacetylenic ketones, the general method II was used. This involves Cadiot-Chodkiewicz coupling $^{5)}$ of propargylic alcohols and 1-bromoacetylenic compounds followed by oxidation, as shown below;

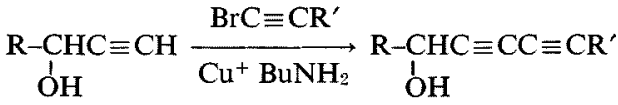

$$
\begin{aligned}
& \underset{\mathrm{MnO}_{2}}{\longrightarrow} \underset{. \mathrm{O}}{\mathrm{R}}-\mathrm{CC} \equiv \mathrm{CC} \equiv \mathrm{CR}^{\prime}
\end{aligned}
$$

\section{Chart 3 ,}

A representative example of the synthetic method is described as follows;

\section{5-(1-Cyclohexenyl)-2,4-pentadiynophenone.}

A solution of $13 \mathrm{~g}$ of phenylethynylcabinol, $50 \mathrm{ml}$ of $n$-butyl-amine, $200 \mathrm{mg}$ of cuprous chloride, $12 \mathrm{~g}$ of hydroxylamine hydrochloride in $200 \mathrm{ml}$ of $99 \%$ ethanol was prepared. To this a solution of $18.5 \mathrm{~g}$ of 1 -cyclohexenyl bromoacetylene in $100 \mathrm{ml}$ of ethanol at $18 \sim 20^{\circ} \mathrm{C}$ was added dropwise under cooling. After stirring for $30 \mathrm{~min}, 1 \mathrm{~g}$ of sodium cyanide was added and the reaction mixture was diluted with water. Extraction of the mixture with ether, washing successively with aqueous sodium carbonate, hydrochloric acid and water, drying and evaporation of the solvent yielded $9.8 \mathrm{~g}$ of crude 1-hydroxyl-5(1-cyclohexenyl)-2,4-pentadiyne.

$$
n_{\mathrm{D}}^{24}=1.6144 \mathrm{IR} \nu_{\max }^{119}: 3350 \mathrm{~cm}^{-1}, 2250 \mathrm{~cm}^{-1}
$$

This oil was dissolved in $200 \mathrm{ml}$ of dried acetone and stirred vigorously with $100 \mathrm{~g}$ of active manganese dioxide for $4 \mathrm{hr}$ at room temperature under an atmosphere of nitrogen. Removal of manganese dioxide from the reaction mixture by filtration and evaporation of the solvent, gave a brown oil, which was chromatographed on silicic acid to yield $4.1 \mathrm{~g}$ of 5 -(1-cyclohexenyl)-2,4-pentadiynophenone, as a pale brown oil. $n_{\mathrm{D}}^{26}=1.6590$. Anal. Found: C, 86.88; H, 6.09. Calcd. for $\mathrm{C}_{17} \mathrm{H}_{14} \mathrm{O}: \mathrm{C}, 87.15 ; \mathrm{H}, 6.02$. IR $\nu_{\max }^{11 \mathrm{q}}: 2215 \mathrm{~cm}^{-1}$,

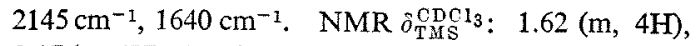
$2.17(\mathrm{~m}, 4 \mathrm{H}), 6.47(\mathrm{q}, 1 \mathrm{H}), 7.3 \sim 7.7(\mathrm{~m}, 3 \mathrm{H}) 8.15(\mathrm{~m}, 2 \mathrm{H})$.

3) Anti-inflammatory activity. Animals used in these tests were fed the pellet diet (CE-2) supplied by CLEA and drinking water ad libitum.

a) Carrageenin-induced edema. Three male rats of the Wistar strain weighing $150 \sim 170 \mathrm{~g}$ were used for each dose level. According to Winter's method, ${ }^{61}$ $0.05 \mathrm{ml}$ of a $1 \%$ carageenin suspension in a sterile saline solution was injected into the plantar tissue of the right hind paw. Test materials suspended in $0.5 \%$ carboxymethylcellulose (CMC) were administered oral- ly $1 \mathrm{hr}$ before the carrageenin injection and the foot volume was determined with a plethysmometer (Plethysmograph $\Delta \mathrm{V}-3$, Ugo Basile, Milano) $4 \mathrm{hr}$ after injection of Carrageenin.

b) Gastric toxicity. The rats which were used in the carrageenin edema test were dissected $72 \mathrm{hr}$ after determination of the foot volume and the effect of the test compound on the gastro-intestinal tract was observed visually.

Degree of toxicity was determined as follows;

$(+++)$ : Serious ulcer, bleeding; body-weight loss

$(++)$ : Medium ulcer, bleeding; body-weight loss

$(+)$ : Slight bleeding, congestion: slight body. weight loss

$( \pm) \quad$ : Very slight congestion or no other change; no weight loss

4) Antimicrobial activity. The tests were performed by the agar streak dilution technique using two fungi and one bacteria as test organisms. Each compound, dissolved in acetone in adequate concentration, was diluted with the culture medium to the final concentration. In all cases the final concentration of acetone was less than $0.5 \%$.

The antimicrobial activity of each test compound was expressed in terms of the minimal inhibitory concentration (MIC) required for complete inhibition of the test microorganism after the incubation period.

The culture conditions for the microorganisms are shown below;

$\begin{array}{lccc}\text { Strain } & \text { Medium } & \begin{array}{c}\text { Temperature } \\ \left({ }^{\circ} \mathrm{C}\right)\end{array} & \begin{array}{c}\text { Incubation } \\ \text { period, } \\ \text { (day) }\end{array} \\ \begin{array}{c}\text { Candida } \\ \text { albicans }\end{array} & \begin{array}{c}\text { Sabouraud } \\ \text { agar }\end{array} & 30 & 3 \\ \begin{array}{c}\text { Trichophyton } \\ \text { rubrum }\end{array} & " & " & 7 \\ \begin{array}{c}\text { Staphyl- } \\ \text { ococcus }\end{array} & \begin{array}{c}\text { Nutrient } \\ \text { agar }\end{array} & 37 & 1 \\ 209 \mathrm{P} & & & \\ & & & \end{array}$

\section{RESULT AND DISCUSSION}

\section{1) Anti-inflammatory activity}

1. Generally speaking, non-steroidal antiinflammatory agents often have such side effects on the gastro-intestinal system as gastric hemorrhage and intestinal perforation. ${ }^{7)}$ In the case of acetylenic ketones, too, as revealed in Table $I$, all the compounds show several grades of gastro-intestinal injury at effective dose (over $30 \%$ inhibition). However, the degrees of gastric injury were so different from each other that we obtained some examples in 
Table I. Inhibition of CarageEnin-INDUCED Edema IN Rats AND Gastric Toxicity Caused By ACETylenic Ketones

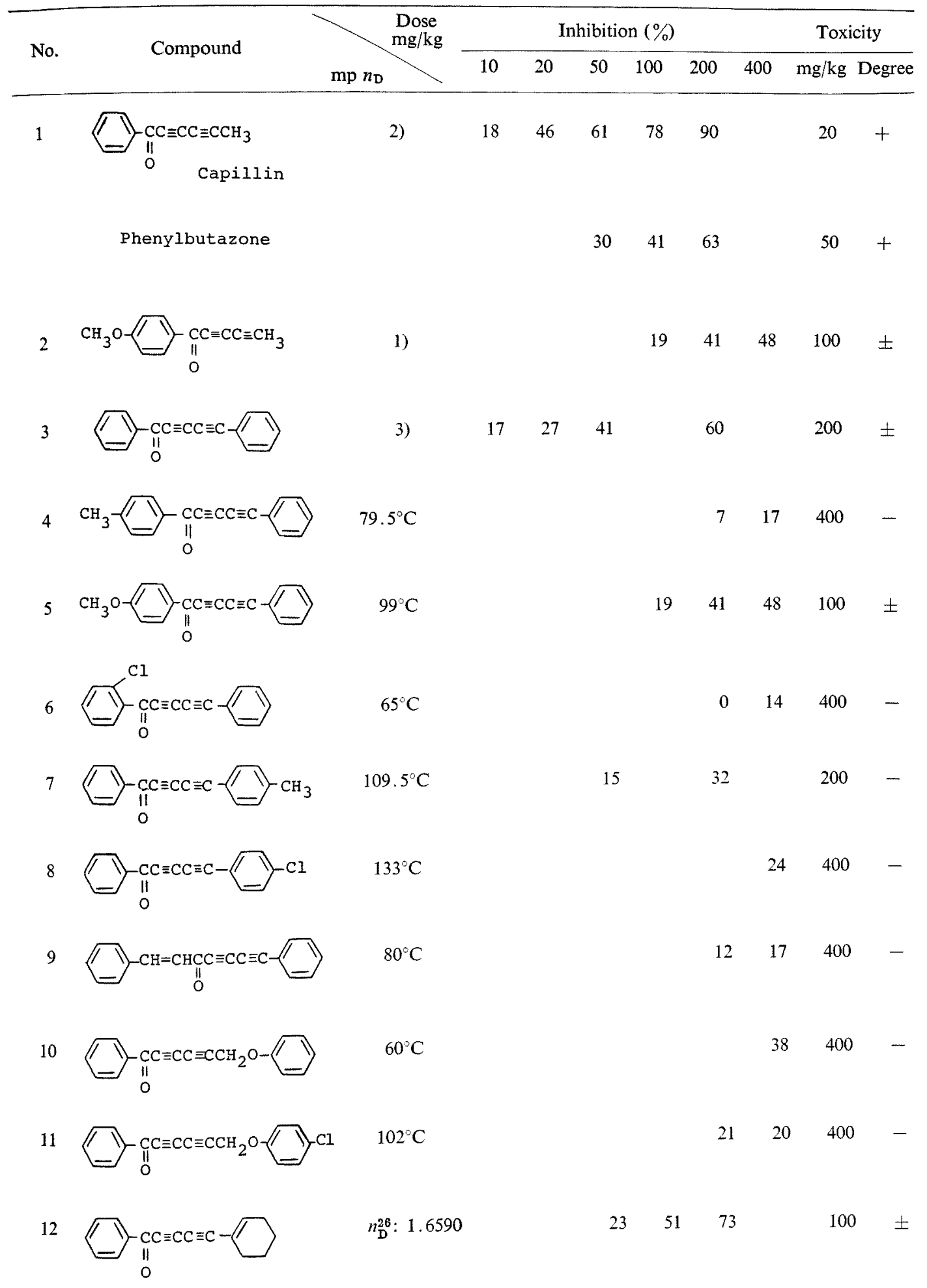




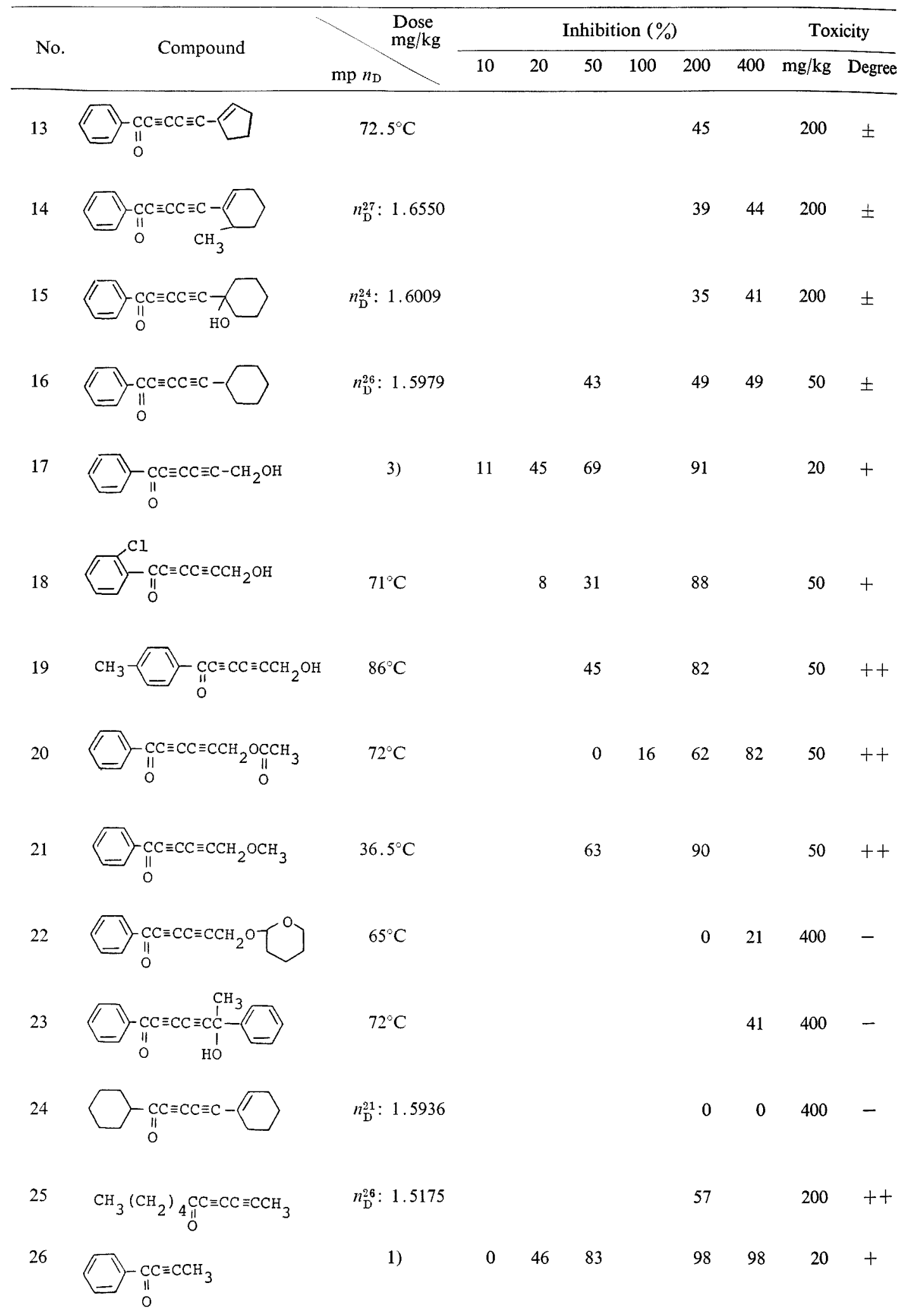




\begin{tabular}{|c|c|c|c|c|c|c|c|c|c|c|}
\hline \multirow{2}{*}{ No. } & \multirow{2}{*}{ Compound } & $\begin{array}{l}\text { Dose } \\
\mathrm{mg} / \mathrm{kg}\end{array}$ & \multicolumn{6}{|c|}{ Inhibition $(\%)$} & \multicolumn{2}{|c|}{ Toxicity } \\
\hline & & & 10 & 20 & 50 & 100 & 200 & 400 & $\mathrm{mg} / \mathrm{kg}$ & Degree \\
\hline 27 & & $n_{\mathrm{D}}^{23}: 1.5196$ & & & 0 & & 15 & 47 & 50 & \pm \\
\hline 28 & & & & & 16 & 27 & 29 & 40 & 50 & \pm \\
\hline 29 & & $61^{\circ} \mathrm{C}$ & & & & & 6 & 49 & 400 & + \\
\hline 30 & & $45^{\circ} \mathrm{C}$ & & & & & 36 & 31 & 400 & \pm \\
\hline 31 & & $55^{\circ} \mathrm{C}$ & & & & & 0 & 0 & 400 & - \\
\hline 32 & & $41^{\circ} \mathrm{C}$ & & & & & 22 & 30 & 200 & \pm \\
\hline 33 & & $62^{\circ} \mathrm{C}$ & & & & & & 19 & 400 & - \\
\hline 34 & & $55^{\circ} \mathrm{C}$ & & & & & & 15 & 400 & - \\
\hline 35 & & $60^{\circ} \mathrm{C}$ & & & & & & 9 & 400 & - \\
\hline 36 & 1 & $100^{\circ} \mathrm{C}$ & & & & & & 11 & 400 & - \\
\hline 37 & . & $n_{\mathrm{D}}: 1.5395$ & & & & & 80 & & 200 & +++ \\
\hline 38 & & $n_{\mathrm{D}}^{27}: 1.6050$ & & & & 11 & 28 & & 200 & \pm \\
\hline 39 & O HO & $n_{\mathrm{D}}^{23}: 1.5670$ & & & & & 62 & 69 & 200 & $+t+$ \\
\hline 40 & $-\underset{\|}{\mathrm{CC}} \equiv \mathrm{CCH}_{2} \mathrm{OH}$ & $n_{\mathrm{D}}^{26}: 1.5841$ & 11 & 22 & 85 & & & & 50 & +++ \\
\hline
\end{tabular}




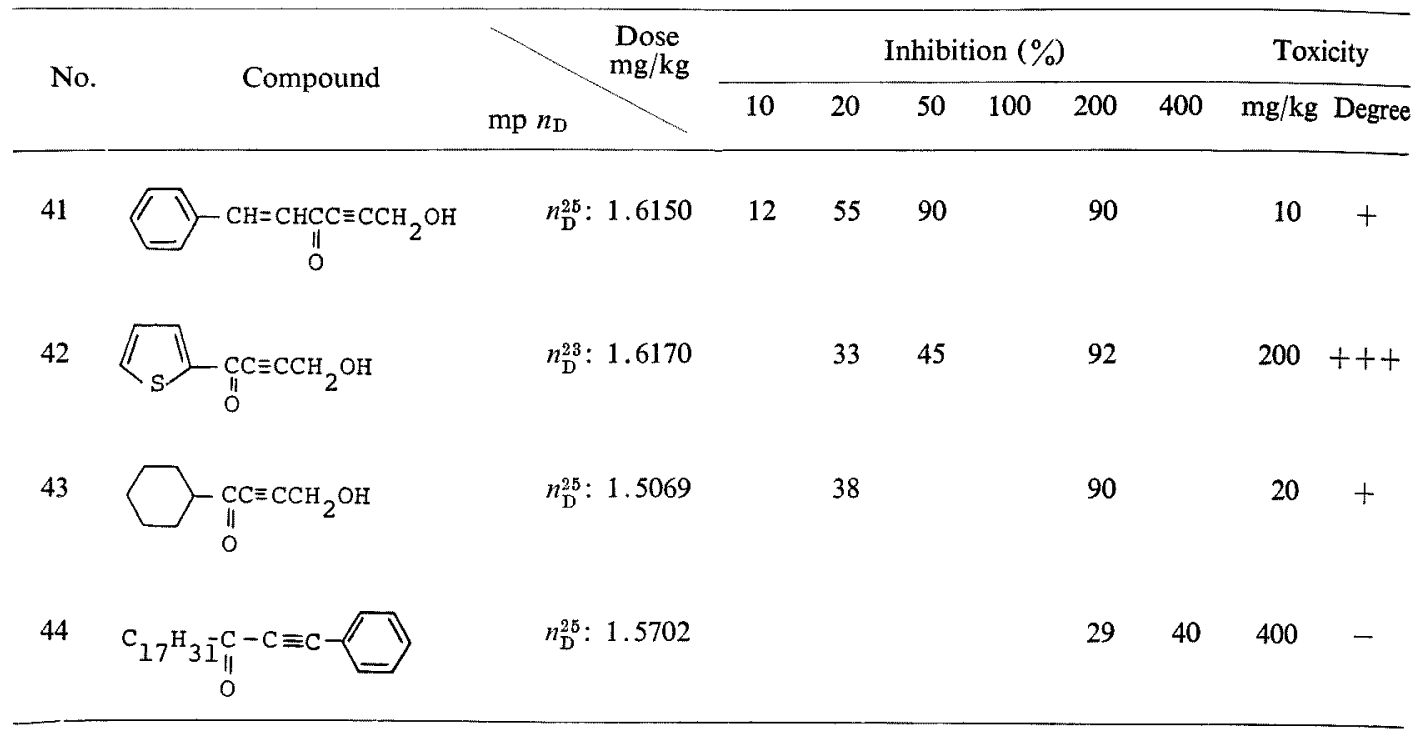

which separation of anti-inflammatory activity from gastric toxicity were reasonably successful. Cycloalkenyl diynophenones (Compound Nos. 12, 13, 14), No. 30 and No. 42 showed neither body-weight loss nor gastric hemorrhage at effective dose.

2. Generally speaking the monoacetylenic ketones may be considered more toxic than the corresponding diacetylenic ketones when Compound Nos. 1, 3, 10, 12 and 16 are compared with Nos. 26, 28, 29, 38 and 39, respectively.

3. Any substituent on a phenyl ring, whether electron-donating or electron-withdrawing, markedly reduced both anti-inflammatory activity and toxicity in any class of compounds, such as the phenyldiynophenone group (Compound Nos. 3 to 8), the phenoxydiynophenone group (Compound Nos. 8 to 9), or the phenoxytetrolophenone group (Compound Nos. 29 to 36 ).

4. Introduction of vinylogous phenyl (Nos. 9, 41), alkyl (Nos. 25, 37, 44) or cycloalkyl (Nos. 24, 43) instead of phenyl in the phenone structure, causes no improvement on either activity or toxicity.

5. There may be a possibility that further elongation of the conjugated ynone system will reduce toxicity without much decrease of antiinflammatory activity, as inferred from results, 1 and 2. But the stability of the compound will be much reduced, too.

6. In conclusion, we can infer that there is a close relation between the anti-inflammatory activity of acetylenic ketones and the irritating action on gastro-intestinal tract, and both the activity and the adverse effect from the ynone system, and that the toxicity can be reduced by substitution of the system or elongation of its conjugation.

\section{2) Antimicrobial activity}

1. As shown in Table II, the novel acetylenic ketones which we obtained in this work reveal higher activity against Trichophyton rubrum than against Candida albicans or Staphylococcus aureus in general agreement with the data, reported by Tanaka et al. ${ }^{1)}$

Oxygen substituted ynophenones, for example, Compound Nos. 17, 21, 15, 34 and 35 were relatively effective against Candida albicans and Compound No. 15, a representative compound, showed some therapeutic effect on rats by oral administration in an in vivo infection experiment.

2. We cannot perceive any relation between anti-Trichophyton activity and gastric toxicity, which may be considered to be local irritating action. Therefore, it can be said that we have obtained a number of novel compounds which are substantially as active as Capillin and much 
Table II. Antimicrobial Activities of Acetylenic Ketones

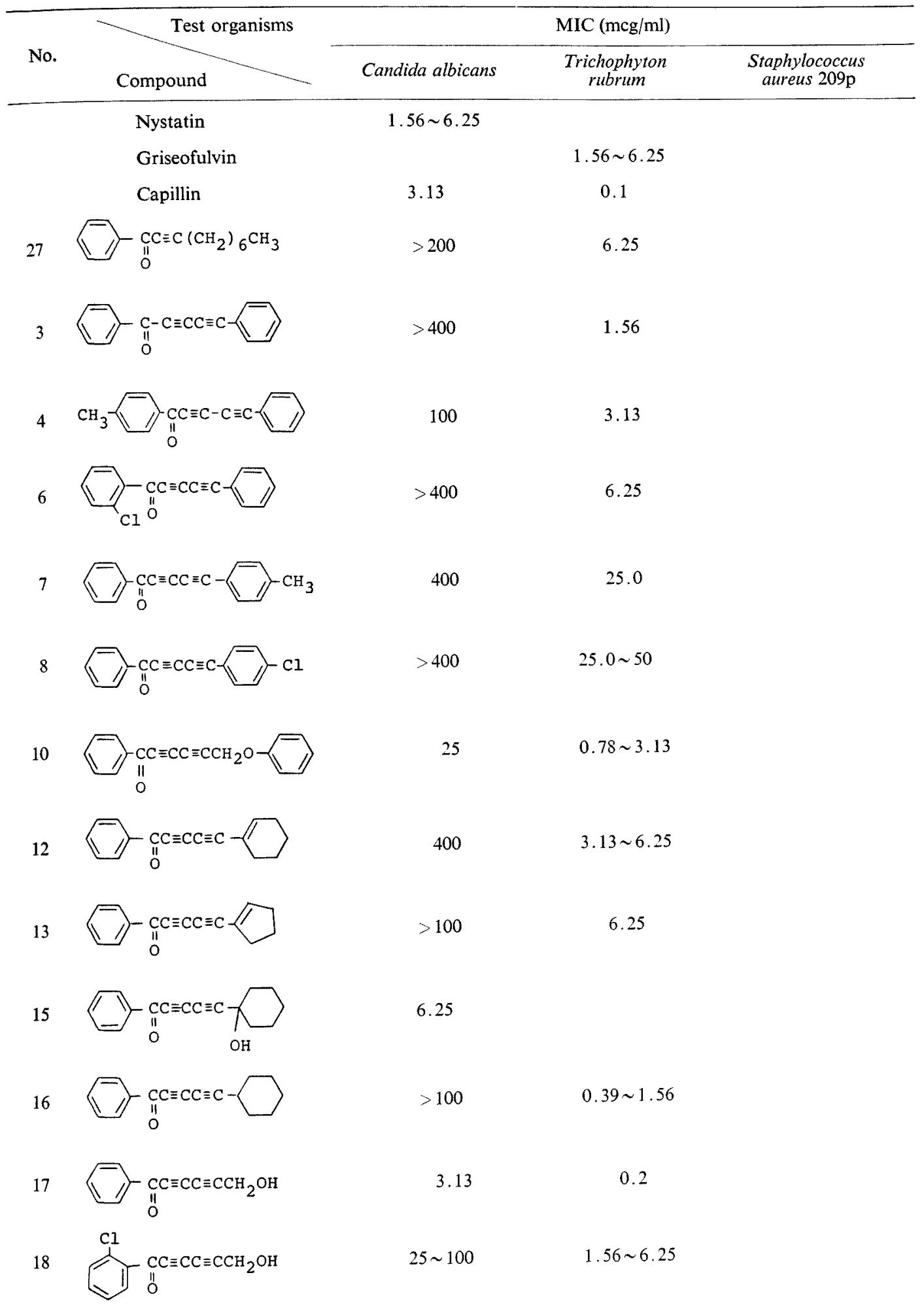




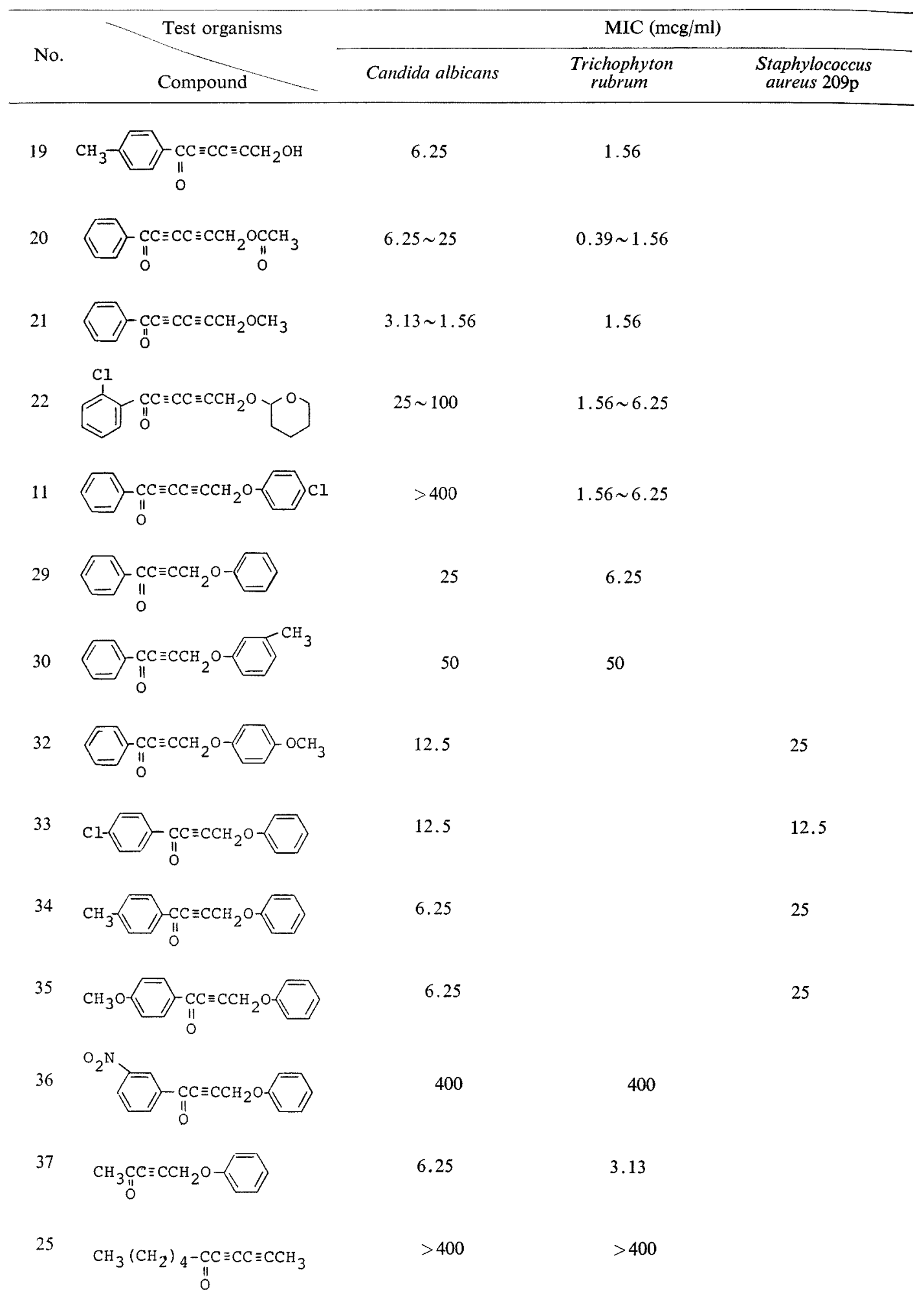




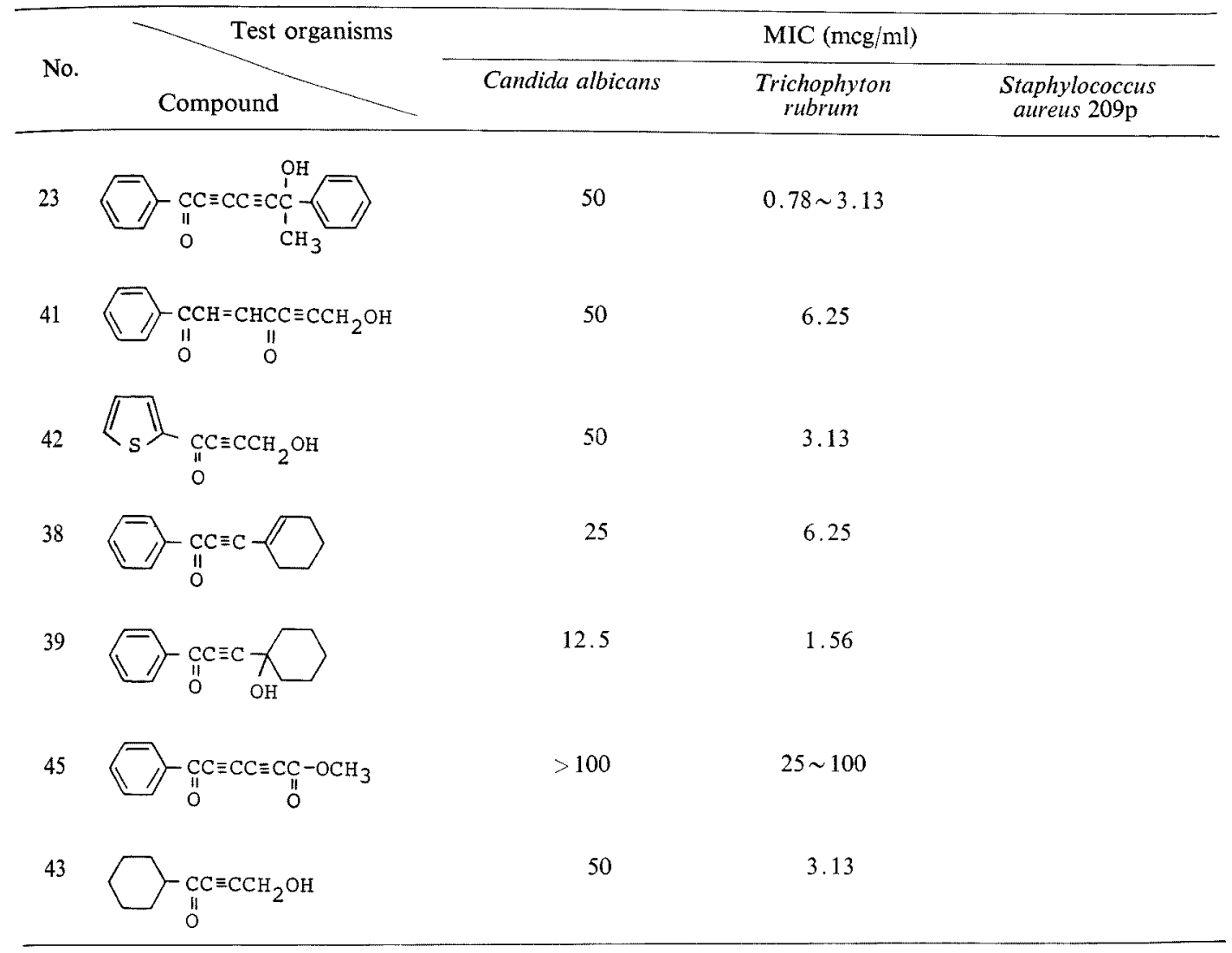

less irritative than Capillin, for example, Compound Nos. 4, 10, 11, 12, 16, 22, 23 and 42 .

3. We cannot apply structure-activity relationship in any other effect than anti-inflammatory activity. Therefore, antimicrobial activity and anti-inflammatory activity of acetylenic ketones are intrinsically different.

Acknowledgement. We wish to thank Proffessor M. Matsui of Tokyo University for his wholehearted encouragement. We are grateful to Drs. S. Yamaoka, S. Saijo, H. Yamamoto, K. Toki, C. Saito and S. Inaba for their useful advices and suggestions. The cooperation of Mr. T. Katsura, Mr. Y. Mizuguchi, and Mrs. Y. Sakai is also acknowledged with gratitude.

\section{REFERENCES}

1) J. Rrisch, W. Spitzner and K. E. Schulte, Arznei- mittel Forschung, 17, 816; K. Tanaka, I. Iwai, Y. Okajima and T. Konotsune, Antibiotics and Chemotherapy, 9, 151 (1959).

2) K. Imai, YAKUGAKU ZASSHI, 76, 405 (1956).

3) B. W. Nash and T. D. Williams, J. Chem. Soc,, 1965, 2983.

4) E. R. H. Jones, L. Skatteböl and M. C. Whiting, J. Chem. Soc., 1956, 4765.

5) G. Eglinton and W. Mcrace, "Advances in Organic Chemistry," vol. 4, John Wiley \& Sons, 1963, p. 225.

6) C. A. Winter, E. A. Risley and G. W. Guss, Proc. Soc. Exptl. Biol. Med., 111, 544 (1962).

7) H. Mizushima, "Inflammation and Anti-inflammatory Agent," Nankodo, Japan, 1970. 